Int. J. of The Soc. of Mat. Eng. for Resources Vol. 6 No. $1 \quad 35 \sim 44$ (1998)

\title{
Original
}

\section{Nuclear Transmutation Reaction Occurring during The Light Water Electrolysis on Pd Electrode.}

\author{
by

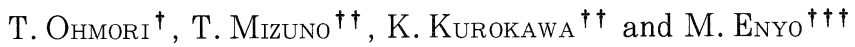

\begin{abstract}
Certain amounts of unexpected elements, eg. $\mathrm{Au}, \mathrm{Fe}, \mathrm{Cu}, \mathrm{Zn}$, and $\mathrm{K}$ with the different isotopic contents evidently different from their natural isotopic abundance were found to be produced on/in Pd electrode by the light water electrolysis. The amounts of $\mathrm{Fe}$ and $\mathrm{Cu}$ reached several at. percent in the vicinity of the electrode surface. The amounts of $\mathrm{Zn}, \mathrm{Au}$ and $\mathrm{K}$ were somewhat smaller. These elements were distributed locally along the scraped edge of the electrode. The distribution of $\mathrm{Au}$ was completely overlapping with that of $\mathrm{Pt}$ partially deposited on the scraped edge of the Pd electrode.
\end{abstract}

Key Words : Nuclear Transmutation Reaction, Light Water Electrolysis, Pd Electrode, Isotopic Deviation

\section{INTRODUCTION}

In the previous work we found that $\mathrm{Fe}$ atoms with anomalous isotopic abundance were produced on/in $\mathrm{Au}$ and $\mathrm{Pd}$ electrodes during the electrolysis in $0.5 \mathrm{M} \mathrm{Na}_{2} \mathrm{SO}_{4}$ and $\mathrm{Na}_{2} \mathrm{CO}_{3}$ light water solutions at a current density of $100 \mathrm{~mA} / \mathrm{cm}^{2}$ [1-4]. On the other hand, we detected many kinds of foreign elements, eg., $\mathrm{Cr}, \mathrm{Fe}, \mathrm{Cu}, \mathrm{Ti}, \mathrm{Sn}, \mathrm{Pt}, \mathrm{Xe}, \mathrm{Pb}$ etc. [5-7] in the element analysis of the Pd electrode after the electrolysis in $0.5 \mathrm{M} \mathrm{LiOH}$ heavy water solution by means of SIMS and EDX. The element production was found also in the electrolysis with $\mathrm{Au}$ electrodes in $0.5 \mathrm{M} \mathrm{Na} \mathrm{SO}_{4}$ and $\mathrm{Na}_{2} \mathrm{CO}_{3}$ light water solutions, in which $\mathrm{Hg}$, $\mathrm{Os}, \mathrm{Kr}, \mathrm{Ni}, \mathrm{Fe}, \mathrm{Si}$ and $\mathrm{Mg}$ were detected when electrolyzing at current densities $>750 \mathrm{~mA} / \mathrm{cm}^{2}[8-9]$. Recently, Miley et al. investigated the excess heat evolution and the reaction products by the electrolysis with $\mathrm{Ni}$ coated bead electrode and reported that some unexpected elements, e.g. $\mathrm{Fe}, \mathrm{Ag}, \mathrm{Cu}, \mathrm{Mg}, \mathrm{Cr}$, etc. were produced on/in the electrode [10]. They report that about $40 \%$ of $\mathrm{Ni}$ electrode material has converted into above elements. In addition, they also report that the isotopic content of ${ }^{57} \mathrm{Fe}$ containing in Fe product has increased significantly, being in comparable with our results obtained with $\mathrm{Au}$ and $\mathrm{Pd}$ electrodes. These results strongly support the idea that some nuclear transmutation reactions take place during the electrolysis in both light and

\footnotetext{
Received October 9, 1997

† Catalysis Research Center, Hokkaido University, Kitaku Sapporo, 060 JAPAN

$\dagger \dagger$ Faculty of Engineering, Hokkaido University, Kitaku Sapporo, 060 JAPAN

$\dagger \dagger \dagger$ Hakodate National College of Technology, Tokura-cho, Hakodate, 042 JAPAN
} 
heavy water solutions.

In the present paper, we report the results investigated about the product elements in the $\mathrm{Pd} /$ $\mathrm{H}_{2} \mathrm{O}$ electrolysis system.

\section{EXPERIMENTAL}

The electrolytic cell was a $300 \mathrm{ml}$ flat-bottomed fused quartz vessel with a $5 \mathrm{~cm}$ thick silicon rubber stopper equipped with a working electrode, counter electrode and quarts glass inlet and outlet tubes for $\mathrm{H}_{2}$ gas. Impurities containing in quarts were as follows : $\mathrm{Al} ;<60$, $\mathrm{Ti} ;<5$, $\mathrm{Fe} ;<4$, $\mathrm{Na}$ $;<4, \mathrm{~K} ;<3, \mathrm{Cu} ;<0.5$ and $\mathrm{B} ;<0.3 \mathrm{ppm}$. The working electrodes used were Pd plates $(99.95 \%$ purity, $5 \mathrm{~cm}^{2}$ app. area, $0.02 \mathrm{~cm}$ thick). Impurities were as follows : $\mathrm{Ag} ; 44$, $\mathrm{Au} ; 23$, Pt ; 20, Fe ; 20, $\mathrm{Si}, \mathrm{Cr} ; 10, \mathrm{Ca} ; 9$ and $\mathrm{Cu} ; 6 \mathrm{ppm}$. The roughness factor of the electrode determined from the double layer capacitance [11] was ca. 2. The electrode surface was scraped with a cleaned glass fragment in order to make crystallographically distorted surface. The counter electrode was a $1 \times 7 \mathrm{~cm}, 80$ mesh Pt gauze. The major impurities were $\mathrm{Rh} ; 18, \mathrm{Pd}, \mathrm{Cr}, \mathrm{Si} ; 2, \mathrm{Cu}, \mathrm{Fe}, \mathrm{B}, \mathrm{Ca} ;<1 \mathrm{ppm}$. The electrolyte solution was $0.5 \mathrm{M} \mathrm{Na}_{2} \mathrm{SO}_{4}$ which was prepared from Merck sprapur grade reagent. The impurities were as follows: $\mathrm{Zn}, \mathrm{Fe}, \mathrm{Mn} ;<0.01, \mathrm{Cu}, \mathrm{Cd} \mathrm{Co}, \mathrm{Ni}, \mathrm{Pb} ;<0.005 \mathrm{ppm}$. The volume of the electrolyte solution was $100 \mathrm{ml}$. The electrolysis was carried out galvanostatically for 7 days at a constant current of $1 \mathrm{~A}$. Before the electrolysis, the working electrode was kept at reversible hydrogen electrode potential by passage of $\mathrm{H}_{2}$ gas into the cell. During the electrolysis, M-Q water was supplied every 24 hours to maintain the concentration of solution. The electrode after the electrolysis was rinsed by $\mathrm{M}-\mathrm{Q}$ water and stored in a cleaned polystyrol case.

The elements on/in Pd electrode after the electrolysis were analyzed by means of AES, EDX, EPMA and SIMS. The AES measurement was made with use of an ANELVA AAS-200 Auger electron spectrometer. The EPMA measurement was made with use of a JEOL JXA-8900 M analyzer. The SIMS measurement was conducted using a HITACHI IMA-3 analyzer in Hitachi Instruments Engineering Company, Ltd.

In this study, the measurement of excess energy was also carried out concurrent with the investigation of the reaction product. The method was described elsewhere $[4,13]$.

\section{RESULTS AND DISCUSSION.}

\section{Elements produced on Pd electrode}

The elements mainly detected on/in a Pd electrode after the electrolysis were relatively light elements with mass numbers below 70. These kinds of elements detected were less than those detected in $\mathrm{Pd} / \mathrm{D}_{2} \mathrm{O}$ electrolysis system [5-7]. In particular, $\mathrm{Hg}, \mathrm{Os}$ and $\mathrm{Hf}$ which are observed in $\mathrm{Pd}$ $/ \mathrm{D}_{2} \mathrm{O}$ and $\mathrm{Au} / \mathrm{H}_{2} \mathrm{O}$ electrolysis systems were not detected in the $\mathrm{Pd} / \mathrm{H}_{2} \mathrm{O}$ electrolysis system. However, as will be described later, a certain amount of $\mathrm{Au}$ was detected locally at a definite scraped edge. Fig. 1 shows relative concentration of elements present on/in a Pd electrode after the electrolysis obtained from SIMS spectrum of 1st scan using the following equation.

$$
\mathrm{C}_{\mathrm{e}}=r \frac{I_{i}}{I_{t}}
$$

where $I_{i}$ and $I_{t}$ are ion intensity of individual elements and compounds and ion intensity of all 


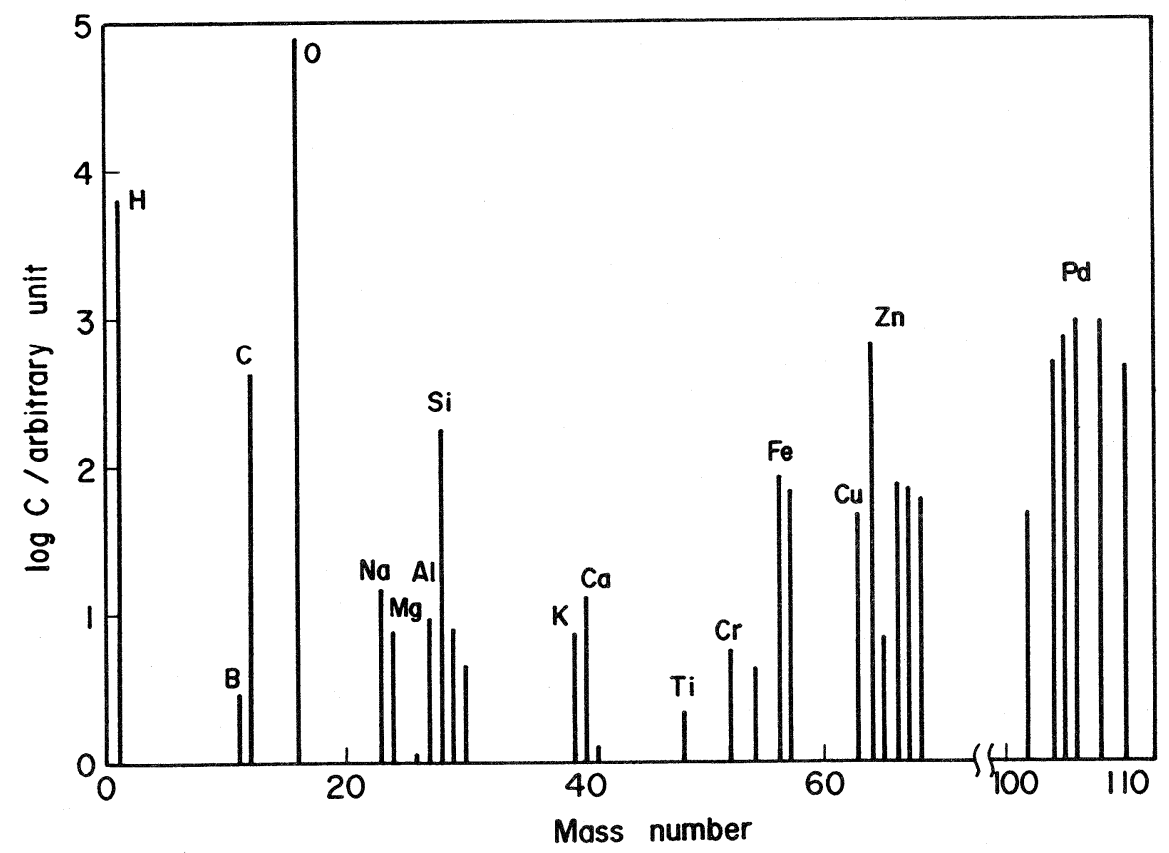

Fig. 1 Relative concentration of the element with mass numbers below 110 present on/in the electrode after electrolysis.

elements and compounds (counts/sec.), respectively, present in the matrix of SIMS, and $r$ is relative sensitivity factor of the corresponding ions. It is seen from this figure that the major elements are ${ }^{64} \mathrm{Zn}, \mathrm{Fe}, \mathrm{Si}, \mathrm{C}, \mathrm{Cu}, \mathrm{Al}, \mathrm{Ca}, \mathrm{K}, \mathrm{Mg}$ and $\mathrm{Na}$ and small amounts of $\mathrm{B}, \mathrm{Ti}, \mathrm{Cr}$ and $\mathrm{Mn}$ are also contained. For the spectrum of mass number 64 , there is a suspicion that the spectra from ${ }^{64} \mathrm{Zn}$ and ${ }^{48} \mathrm{TiO}$ are overlapping, however, the intensity of spectrum of ${ }^{48} \mathrm{Ti}$ is much smaller than that of mass number 64 , hence, the greater part of the spectrum of mass number 64 can be assigned to the spectrum from $\mathrm{Zn}$. The concentration of $\mathrm{C}$ is high which, however, markedly decreased within several scan numbers. Therefore, $\mathrm{C}$ atoms are considered to be localized at the electrode surface as a result of contamination.

Fig. 2 shows a typical AES spectra. One can distinguish $\mathrm{Pt}, \mathrm{Fe}, \mathrm{Cu}$ and $\mathrm{Cd}$ signals from the spectrum without $\mathrm{Ar}$ ion bombardment treatment. The signals of $\mathrm{Pt}, \mathrm{Cu}$ and $\mathrm{Cd}$ atoms disappeared immediately when starting Ar ion bombardment, hence, it is seen that these elements are distributed only in the vicinity of the electrode surface, the amount of which being within a few at. percent at most even at the top surface. While the signals of Fe atom were still detected after several minutes of the bombardment. The distribution profile of Fe atoms in the electrode estimated from AES spectra is shown in Fig. 3. One can see from this figure that the atomic content of Fe reaches $20 \%$ at the top surface of the electrode. The concentration of $\mathrm{Fe}$ atoms passes through maximum at several mono-layers from the surface and decreases gradually over ca. 100 mono-layers. Thus, the total amount of $\mathrm{Fe}$ produced is estimated at $c a .8 \times 10^{16}$ atoms. These results are qualitatively 


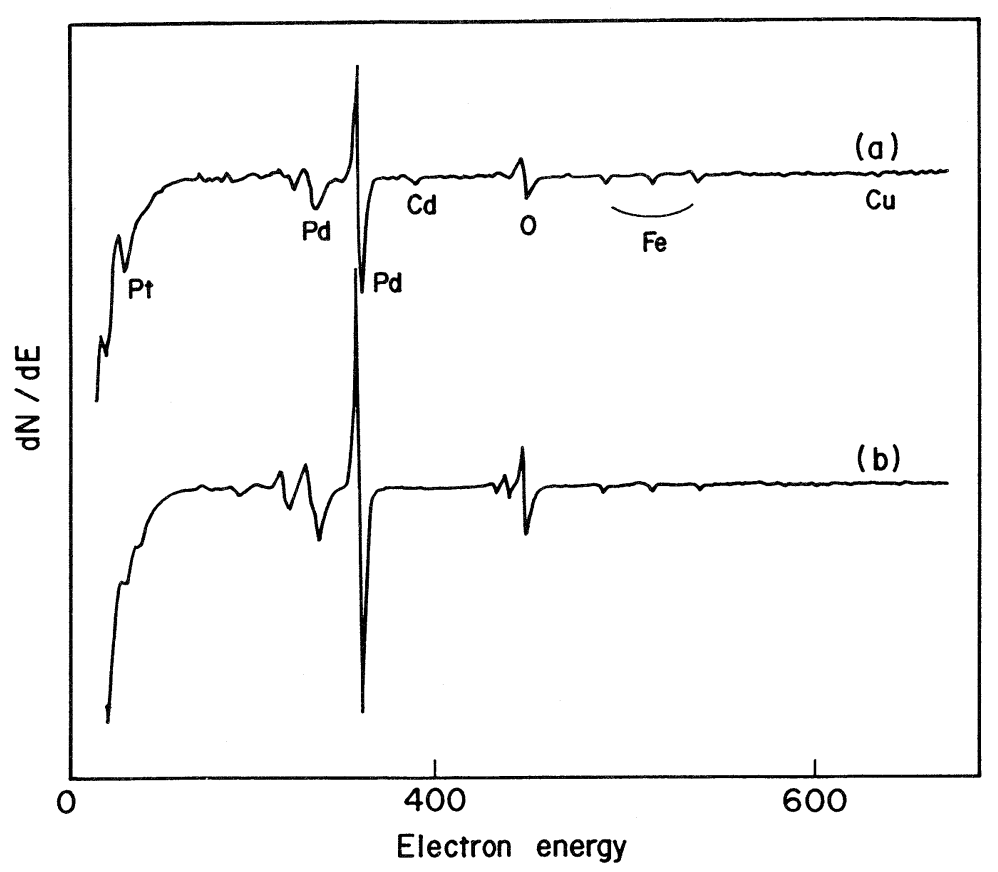

Fig. 2 AES spectrum of the top surface of Pd electrode after electrolysis.

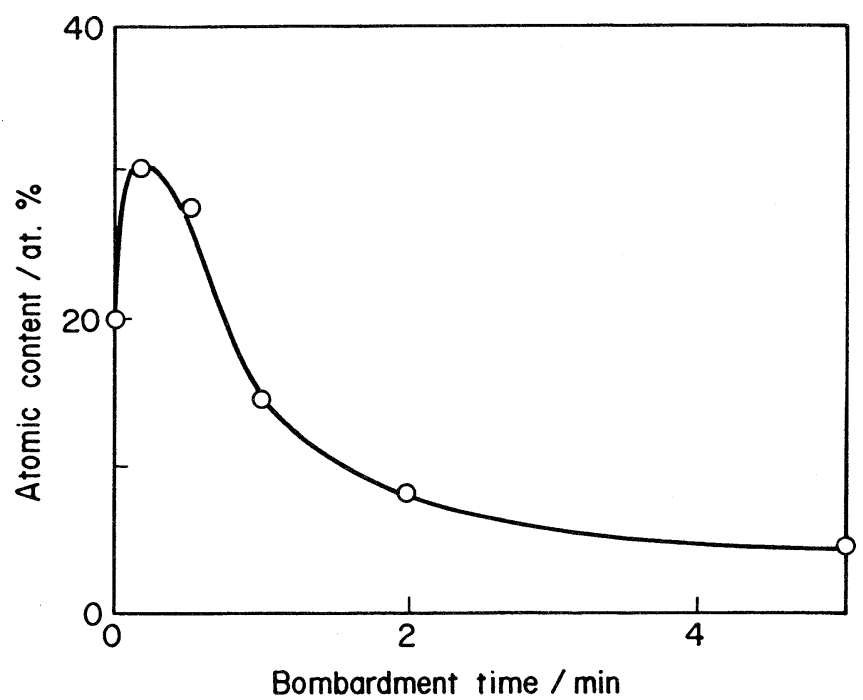

Fig. 3 Distribution profile of Fe atoms in Pd electrode after electrolysis. 
analogous to those obtained previously [2]. The SIMS signals corresponding to Pt were near the background levels which looks to be incompatible with the result of AES. This may be attributed to the low sensitivity of $\mathrm{Pt}$ for SIMS analysis by the $\mathrm{O}_{2}{ }^{+}$irradiation and the localization of Pt distribution on/in Pd electrode as will be shown later.

\section{Isotopic distribution of the elements}

The elements having plural stable isotopes detected on/in the Pd electrode after the electrolysis can be divided into two groups. One is the elements which underwent significant deviation from natural isotopic abundance. The other is the elements which underwent little deviation. The elements, $\mathrm{K}, \mathrm{Fe}, \mathrm{Cu}$, and $\mathrm{Zn}$, are classified in the former group, the isotopic distribution profiles of which obtained by SIMS analysis are shown in Figs. 4-7.

For $\mathrm{K}$, a slight isotopic deviation was observed. At the top surface the content of ${ }^{39} \mathrm{~K}$ decreased down to $84 \%$, deviating $9 \%$ from natural isotopic abundance. The content of ${ }^{41} \mathrm{~K}$ increased correspondingly. The degree of deviation becomes much smaller with increasing the depth of the electrode, approaching their natural isotopic abundance. This suggests that impurity $\mathrm{K}$ atoms are present to some extent in the Pd electrode material. The total amount of $\mathrm{K}$ detected is very small, therefore, the reaction to produce $\mathrm{K}$ atoms, as a whole, would not be substantial.

For $\mathrm{Fe}$, a remarkable increase in ${ }^{57} \mathrm{Fe}$ was observed, the amount of which reached 43 at. percent at the top surface, exceeded 21 times its natural isotopic abundance. On the contrary, the content of ${ }^{56} \mathrm{Fe}$ decreased correspondingly. The increase in ${ }^{57} \mathrm{Fe}$ was observed in the previous works carried out in $\mathrm{Pd} / \mathrm{H}_{2} \mathrm{O}[2]$ and $\mathrm{Pd} / \mathrm{D}_{2} \mathrm{O}$ [5-7] electrolysis systems, however the extent of the deviation in

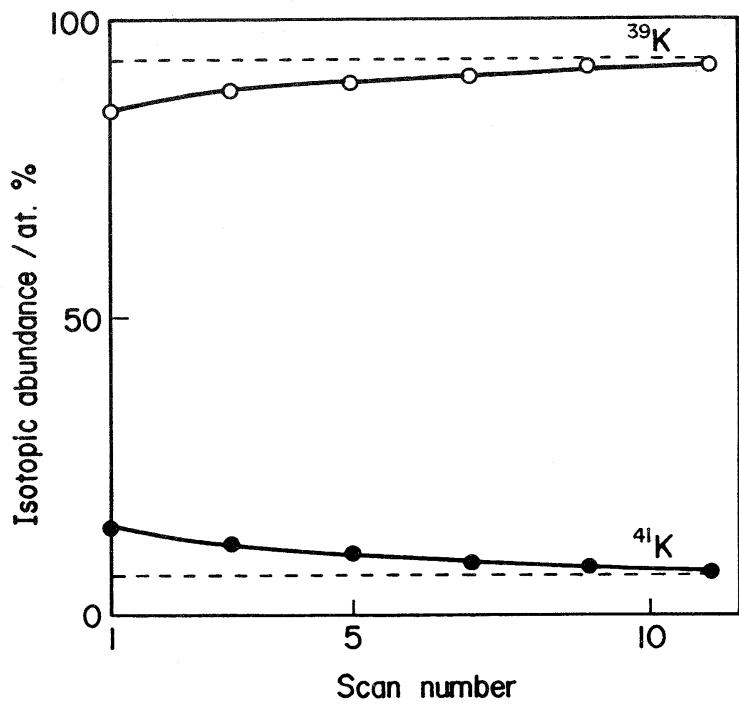

Fig. 4 Isotopic distribution of $\mathrm{K}$ present on/in the electrode after electrolysis, (O) ${ }^{39} \mathrm{~K}$, (-) ${ }^{11} \mathrm{~K}$. Dashed lines show the natural isotopic abundance levels of individual isotopes.

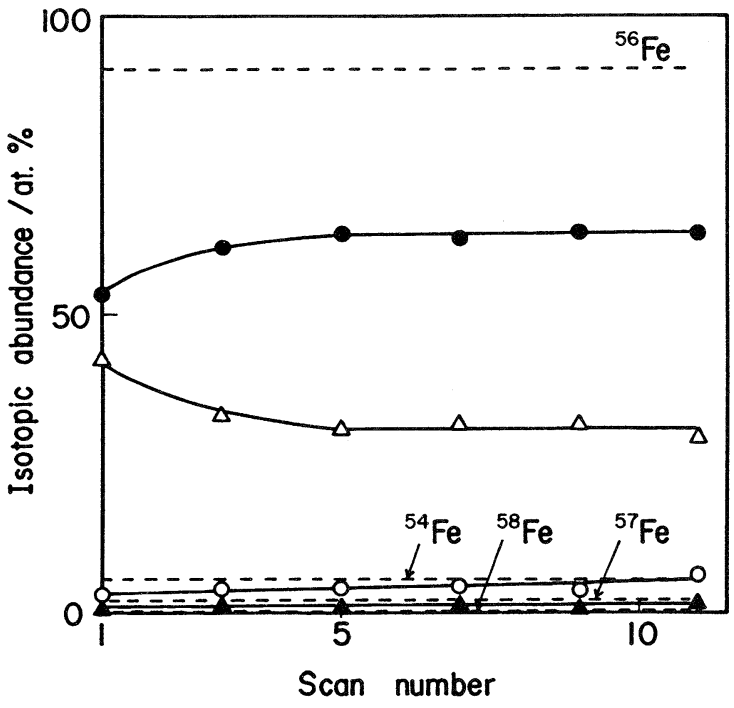

Fig. 5 Isotopic distribution of $\mathrm{Fe}$ present on/in the electrode after electrolysis, $(O)$ ${ }^{54} \mathrm{Fe},(\bullet){ }^{56} \mathrm{Fe},(\triangle){ }^{57} \mathrm{Fe},(\boldsymbol{\Delta}){ }^{58} \mathrm{Fe}$. Dashed lines show the natural isotopic abundance levels of individual isotopes. 


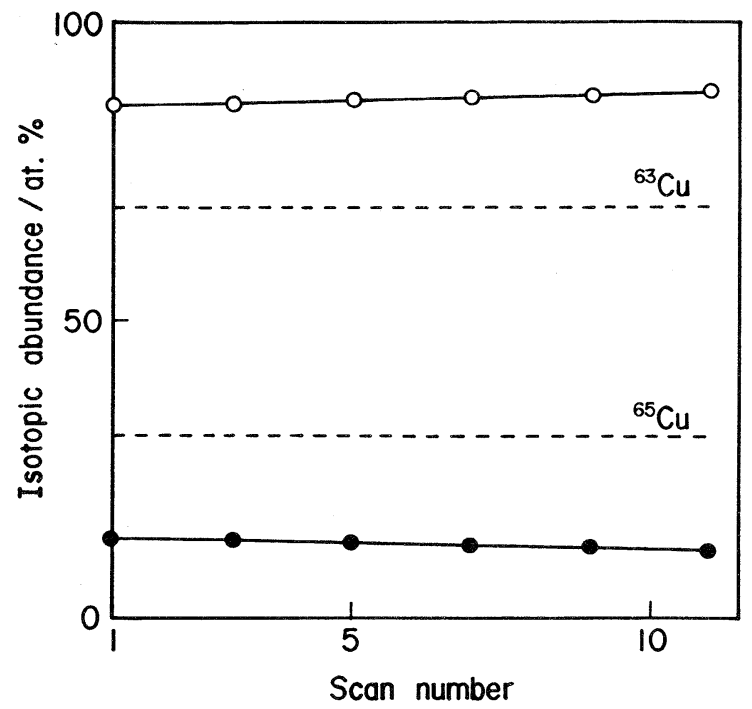

Fig. 6 Isotopic distribution of $\mathrm{Cu}$ present on/in the electrode after electrolysis, $(\bigcirc)$ ${ }^{63} \mathrm{Cu}$. ( ${ }^{65} \mathrm{Cu}$. Dashed lines show the natural isotopic abundance levels of individual isotopes.

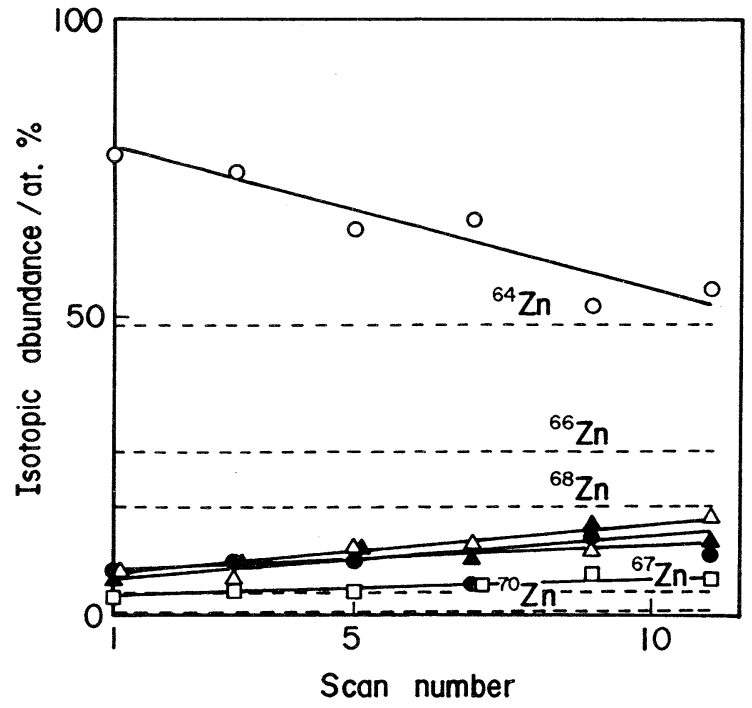

Fig. 7 Isotopic distribution of $\mathrm{Zn}$ present on/in the electrode after electrolysis, $(\bigcirc){ }^{64} \mathrm{Zn}$, (•) ${ }^{66} \mathrm{Zn},(\triangle){ }^{67} \mathrm{Zn},(\mathbf{\Delta}){ }^{68} \mathrm{Zn},(\square){ }^{70} \mathrm{Zn}$.

this case was far greater. In the former system, the content of ${ }^{57} \mathrm{Fe}$, unlike the result of this case, was somewhat smaller in the vicinity of the electrode surface. Hence, there is a suspicion that impurity Fe atoms are mixing more or less from electrolyte reagents or cell materials in the previous work, reducing the content of ${ }^{57} \mathrm{Fe}$ particularly in the vicinity of the electrode surface. In the present work the content of ${ }^{54} \mathrm{Fe}$ was below its natural isotopic abundance. Therefore, the result in the previous work [2], in which the content of ${ }^{54} \mathrm{Fe}$ reached 16 at. percent, is in contradiction with the result of the present work. In the SIMS measurement of the previous work, a considerable strong $\mathrm{Al}^{+}$signal corresponding to $7.7 \%$ of the total signal intensity was observed which was 3 times greater than in the present work. Perhaps, this leads to an error in the quantification of ${ }^{54} \mathrm{Fe}$ of the previous work owing to the overlapping of the spectrum of $\mathrm{Al}_{2}{ }^{+}$on ${ }^{54} \mathrm{Fe}^{+}$spectrum.

For $\mathrm{Cu}$, the content of ${ }^{63} \mathrm{Cu}$ increased from $69.1 \%$ of its natural value to $85-88 \%$, while the content of ${ }^{65} \mathrm{Cu}$ decreased. Similar tendency was observed in $\mathrm{Pd} / \mathrm{D}_{2} \mathrm{O}$ system [5-7], although, in that case, the degree of the increase in ${ }^{63} \mathrm{Cu}$ was more conspicuous.

For $\mathrm{Zn}$, the content of ${ }^{64} \mathrm{Zn}$ increased particularly in the vicinity of the electrode surface whereas the contents of ${ }^{67} \mathrm{Zn}$ and ${ }^{70} \mathrm{Zn}$ increased with increasing depth. The contents of ${ }^{66} \mathrm{Zn}$ and ${ }^{68} \mathrm{Zn}$ were below their natural isotopic abundance, specifically, the decrease of the former isotope was pronounced. The contents of ${ }^{64} \mathrm{Zn}$ and ${ }^{68} \mathrm{Zn}$ approached natural isotopic abundance with increasing depth of the electrode. The trend of the deviation of $\mathrm{Zn}$ is opposite to that in $\mathrm{Pd} / \mathrm{D}_{2} \mathrm{O}$ system [5-7] in that the content of ${ }^{64} \mathrm{Zn}$ increases and the contents of ${ }^{66} \mathrm{Zn}$ and ${ }^{67} \mathrm{Zn}$ decrease. The reason why such difference was caused is still unknown. It may be attributed to the difference in the reaction 
scheme between $\mathrm{Pd} / \mathrm{H}_{2} \mathrm{O}$ and $\mathrm{Pd} / \mathrm{D}_{2} \mathrm{O}$ systems.

It is possible to concentrate a chosen isotope of an element chemically or physically utilizing isotopic effect in the case of light elements, eg. H, Li, C, O etc. However, it is nearly impossible in the case of $\mathrm{K}, \mathrm{Fe}, \mathrm{Cu}$ and $\mathrm{Zn}$ without use of nuclear reaction. Therefore, $\mathrm{Fe}, \mathrm{Cu}, \mathrm{Zn}$ and part of $\mathrm{K}$ present on/in the Pd electrode are considered to be the products of nuclear reaction. It is found from these results that the yield of above elements and their isotopic deviations are not differ much from those obtained in $\mathrm{Pd} / \mathrm{D}_{2} \mathrm{O}$ system, although there is a certain difference in the isotopic deviation in $\mathrm{Zn}$. Hence, we can assume that the analogous nuclear processes, concerning the production of above elements, would occur in $\mathrm{Pd} / \mathrm{H}_{2} \mathrm{O}$ and $\mathrm{Pd} / \mathrm{D}_{2} \mathrm{O}$ systems.

The other elements, eg., $\mathrm{Li}, \mathrm{B}, \mathrm{Mg}, \mathrm{Si}, \mathrm{Ca}$ and $\mathrm{Cr}$ were very close to their natural isotopic abundance (Table I). These elements would not be nuclear reaction products but impurities. The distribution of $\mathrm{Si}$ on $\mathrm{Pd}$ electrode was found to be extremely localized from the EPMA analysis. Therefore we consider that the $\mathrm{Si}$ atons are those containing in glass slightly remained on/in $\mathrm{Pd}$

TABLE 1 Tsotopic contents of the light elements present on/in palladium electrode after the electrolysis

\begin{tabular}{|c|c|c|c|c|}
\hline \multirow[t]{2}{*}{ Element } & \multicolumn{3}{|c|}{ isotopic content } & \multirow{2}{*}{$\begin{array}{l}\text { natural isotopic } \\
\text { abundance } \\
\text { (at.\%) }\end{array}$} \\
\hline & 1st scan & $\begin{array}{l}\text { 2nd scan } \\
\text { (at.\%) }\end{array}$ & 3 rd scan & \\
\hline${ }^{6} \mathrm{Li}$ & 6.8 & 8.3 & - & 7.4 \\
\hline${ }^{7} \mathrm{Li}$ & 93.2 & 91.7 & - & 92.6 \\
\hline${ }^{10} \mathrm{~B}$ & 27.2 & 22.2 & 16.4 & 19.2 \\
\hline${ }^{11} \mathrm{~B}$ & 72.8 & 77.8 & 83.6 & 80.8 \\
\hline${ }^{24} \mathrm{Mg}$ & 78.3 & 77.7 & 78.6 & 78.6 \\
\hline${ }^{25} \mathrm{Mg}$ & 9.4 & 10.6 & 11.3 & 10.1 \\
\hline${ }^{26} \mathrm{Mg}$ & 11.2 & 11.6 & 10.1 & 11.2 \\
\hline${ }^{28} \mathrm{Si}$ & 89.1 & 91.2 & 90.9 & 92.2 \\
\hline${ }^{29} \mathrm{Si}$ & 7.0 & 5.4 & 5.6 & 4.7 \\
\hline${ }^{30} \mathrm{Si}$ & 3.9 & 3.3 & 3.5 & 3.1 \\
\hline${ }^{40} \mathrm{Ca}^{*}$ & 95.0 & 95.4 & 95.0 & 96.9 \\
\hline${ }^{42} \mathrm{Ca}^{*}$ & 1.3 & 1.2 & 1.4 & 0.64 \\
\hline${ }^{43} \mathrm{Ca}^{*}$ & 1.5 & 1.1 & 1.5 & 0.13 \\
\hline${ }^{52} \mathrm{Cr}^{* *}$ & 82.2 & 82.3 & 81.5 & 83.8 \\
\hline${ }^{53} \mathrm{Cr}^{* *}$ & 11.0 & 10.9 & 11.8 & 9.6 \\
\hline
\end{tabular}

* In calculation of ${ }^{40} \mathrm{Ca}$, ${ }^{42} \mathrm{Ca}$ and ${ }^{43} \mathrm{Ca}$, the contents of ${ }^{44} \mathrm{Ca}$ and ${ }^{48} \mathrm{Ca}$ are taken to be equal to natural isotopic abundance because there is a possibility of overlapping of spectra of $\mathrm{SiO}^{+}$and $\mathrm{Ti}^{+}$.

** In calculation of ${ }^{52} \mathrm{Cr}$ and ${ }^{58} \mathrm{Cr}$, the contents of ${ }^{50} \mathrm{Cr}$ and ${ }^{54} \mathrm{Cr}$ are taken to be equal to natural isotopic abundance because of a possibility of overlapping of spectra of $\mathrm{Ti}^{+}$ and $\mathrm{Fe}^{+}$. 


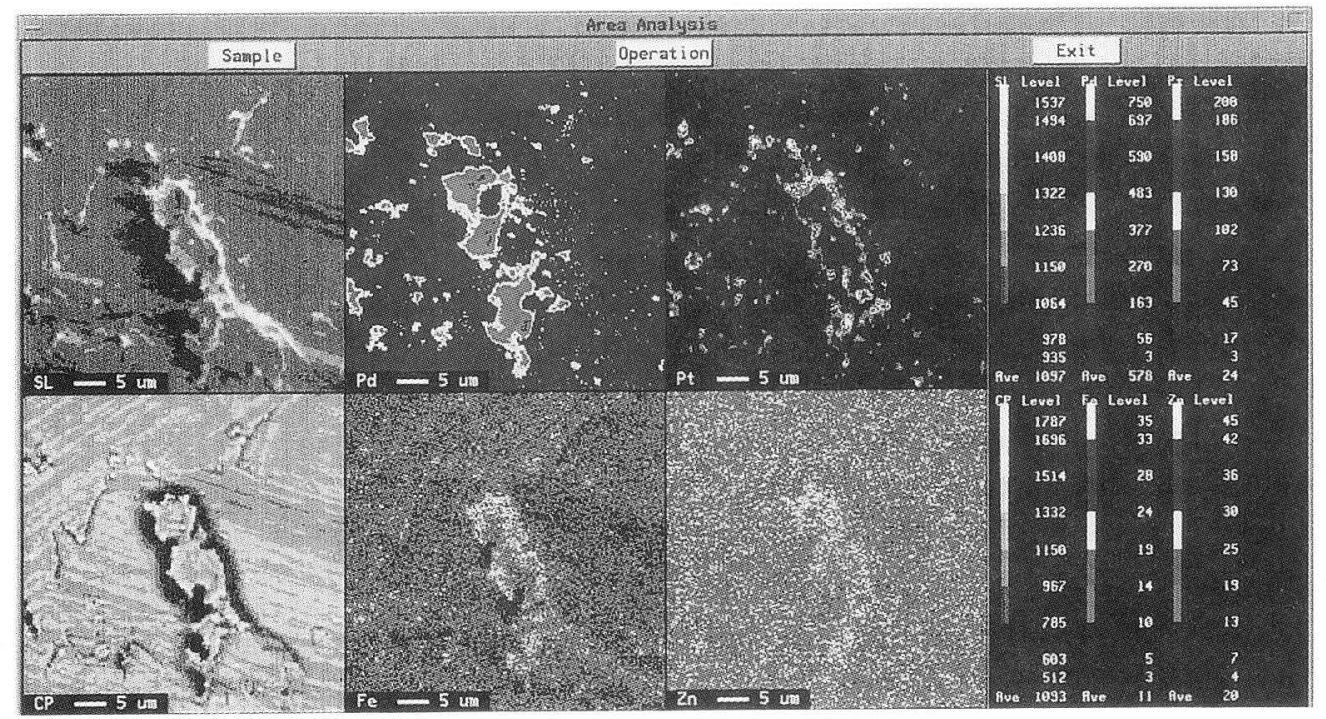

Fig. 8 EPMA images of Pd, Fe, Pt and Zn. on the electrode surface after the electrolysis.

electrode as well as $\mathrm{Al}$ and $\mathrm{B}$ when scraping. All of these elements have smaller mass numbers compared to $\mathrm{Fe}, \mathrm{Cu}$, and $\mathrm{Zn}$. This suggests that $\mathrm{Fe}, \mathrm{Cu}$ and $\mathrm{Zn}$ are not produced as a result of nuclear fusion reactions through the formation of $\mathrm{Li}, \mathrm{B}, \mathrm{Mg}$. Si, or Ca.

Besides these elements a considerable amount of $\mathrm{Pt}$ is also present on/in $\mathrm{Pd}$ electrode. The isotopic distribution of Pt measured by SIMS (by the irradiation of $\mathrm{Cs}^{-}$) was very close to its natural isotopic abundance. Therefore we consider that Pt was transferred from the counter electrode.

The distribution of Fe, Zn, Pt and Au on/in Pd electrode

The distribution of $\mathrm{Fe}, \mathrm{Zn}$ and $\mathrm{Pt}$ on/in $\mathrm{Pd}$ electrode after the electrolysis was investigated by EPMA. Fig. 8 shows the EPMA images of Pd, Fe, $\mathrm{Zn}$ and Pt distributed on/in Pd electrode. Two pictures on the left hand side are SEM images of the Pd electrode surface. In the middle of the pictures, a piece a little peeling and some scraped marks are visible. Four other pictures show the EPMA images of Pd, Fe, Pt and $\mathrm{Zn}$ obtained at the same surface. As seen, strong distribution of Fe is observed along the scraped edge, particularly along the edge of a piece in the middle. Pt and Zn are also concentrated along the scraped edge. This supports that the nuclear reaction takes place exclusively at the scraped edge where the lattice defects or cracks are concentrated. The intensity of EPMA image was in the order $\mathrm{Zn}<\mathrm{Pt}<\mathrm{Fe}$. The less intensity of $\mathrm{Zn}$ compared to $\mathrm{Fe}$, which is consistent with the result of AES, is incompatible with the result of SIMS. Therefore the SIMS spectrum is considered to be the one from the specific part where $\mathrm{Zu}$ is distributed abundantly.

At a part of the edge of the distorted surbace of the electrode where Pt localized strongly, a strong localization of Au was also observed. Fig. 9 shows the EPMA images of Pd, Pt and $\mathrm{Au}$ on that part together with the SEM image. As described already $20 \mathrm{ppm}$ of $\mathrm{Au}$ is contained in $\mathrm{Pd}$ electrode material and no detectable $\mathrm{Au}$ is contained in Pt counter electrode and quartz materials. 
(a)

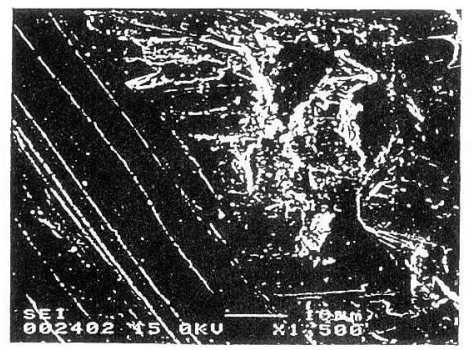

(b)

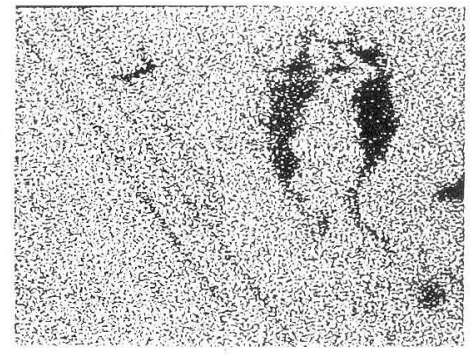

(c)

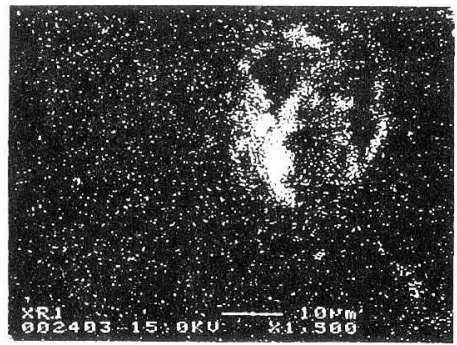

(d)

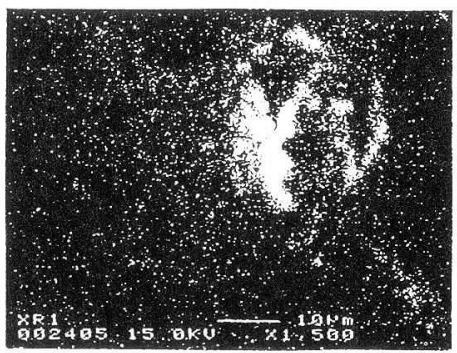

Fig. 9 EPMA images of Pd, Pt and Au on the electrode surface after the electrolysis, (a) SEM image of the electrode sample, (b) Pd image, (c) Pt image, (d) Au image.

Such a small amount of $\mathrm{Au}$ in $\mathrm{Pd}$ is improbable to be detected by EPMA. Of course, on the Pd electrode before electrolysis Au was not detected. Dash et. al. reported that comparable amounts of $\mathrm{Au}$ and $\mathrm{Pt}$ were exclusively formed on the rough part of $\mathrm{Pd}$ electrode surface after the electrolysis in both $\mathrm{H}_{2} \mathrm{SO}_{4}$ light and $\mathrm{H}_{2} \mathrm{SO}_{4}$ heavy water solutions [12]. The result obtained in the present work is completely consistent with above result. The perfect overlapping of the distributions of $\mathrm{Pt}$ and $\mathrm{Au}$ observed in the present experiment suggests that the production of $\mathrm{Au}$ is strongly related to $\mathrm{Pt}$.

Surface structure of the electrode after the electrolysis

As seen from SEM pictures in Figs. 8 or 9 there is little difference in the surface structure of $\mathrm{Pd}$ electrodes before and after the electrolysis. Similar result was obtained with an Au electrode when electrolyzed for 7 days at current densities $<100 \mathrm{~mA} / \mathrm{cm}^{2}$ [1-4]. For an $\mathrm{Au}$ electrode, we observed the development of a number of micro craters and the production of precipitates of some $100 \mu \mathrm{g}$ containing unexpected heavy metal elements with anomalous isotopic distributions when electrolyzing for 20-30 days at current densities $>200 \mathrm{~mA} / \mathrm{cm}^{2}$ [8-9]. So far, in the case of Pd electrode, we do not try to carry out the electrolysis at above high current densities. In this connection, we are going to make observation in near future.

\section{Reaction scheme}

As seen from Fig. 9, the distribution of Au produced on Pd electrode was completely coincide with that of $\mathrm{Pt}$. On the basis of this fact we consider that $\mathrm{Au}$ is produced from $\mathrm{Pt}$ by the following reaction, 


$$
{ }^{196} \mathrm{Pt}+{ }^{1} \mathrm{H} \rightarrow{ }^{197} \mathrm{Au}
$$

However the nuclear reactions to produce $\mathrm{Fe}, \mathrm{Cu}$ and $\mathrm{Zn}$ are much more complex.

As mentioned above a small amount of $\mathrm{Cd}$ was detected by AES analysis, although the isotopic distribution could not be determined owing to the overlapping of $\mathrm{Pd}^{+}$and $\mathrm{Fe}_{2}^{+}$spectra on $\mathrm{Cd}^{+}$spectrum. Therefore, the following reactions are considered to be most feasible,

$$
\begin{aligned}
& { }^{104} \mathrm{Pd}+2{ }^{1} \mathrm{H} \rightarrow{ }^{106} \mathrm{Cd} \\
& { }^{106} \mathrm{Cd} \rightarrow{ }^{57} \mathrm{Fe}+{ }^{23} \mathrm{Ne}+{ }^{22} \mathrm{Ne}+{ }^{4} \mathrm{He} \\
& { }^{23} \mathrm{Ne} \rightarrow{ }^{23} \mathrm{Na}+\beta \\
& { }^{102} \mathrm{Pd}+2{ }^{1} \mathrm{H} \rightarrow{ }^{103} \mathrm{Ag} \\
& { }^{103} \mathrm{Ag} \rightarrow{ }^{63} \mathrm{Cu}+{ }^{40} \mathrm{Ar} \\
& { }^{102} \mathrm{Pd}+2{ }^{1} \mathrm{H} \rightarrow{ }^{104} \mathrm{Cd} \\
& { }^{104} \mathrm{Cd} \rightarrow{ }^{64} \mathrm{Zn}+{ }^{40} \mathrm{Ar}
\end{aligned}
$$

The characteristics that $\mathrm{Fe}, \mathrm{Zn}$ and Au were concentrated along the scraped edge of the electrode are the same as in the case of $\mathrm{Au} / \mathrm{H}_{2} \mathrm{O}$ system [8-9]. This shows that such roughed surface plays an important role for the nuclear reactions. As have discussed in the previous paper [2], the hydrogen concentration around the edge where the lattice defects are highly distributed would become very high and the electron density becomes extremely stronger. Under such condition, the sheltering effect by the electrons would become effective between $\mathrm{Pd}$ and $\mathrm{H}$ atoms which allows $\mathrm{H}$ atoms to approach $\mathrm{Pd}$ or Pt atoms enough to cause the nuclear reaction as have proposed by Miley [10].

For $\mathrm{Pd} / \mathrm{H}_{2} \mathrm{O}$ system, the mean value of the excess energies observed $9 \mathrm{Pd}$ electrodes was $265 \mathrm{~mW}$ ( $604 \mathrm{~mW}$ max. and $-16 \mathrm{~mW}$ min.). The evolution of such a small amount of excess energy would be understandable, if above reaction scheme is accepted, because both the endothermic and the exothermic reactions are included. In addition, the scattering of excess energy suggests that the reaction scheme changes delicately depending on the slight structural difference of the electrode surface.

\section{REFERENCES}

1. T.Ohmori and M.Enyo, ICCF-4 Notebook, N.2, 3 (1993).

2. T.Ohmori, T.Mizuno and M.Enyo, J. New Energy, Vol.1, No.1, 15 (1996).

3. T.Ohmori, T.Mizuno, H.Minagawa and M.Enyo, Int. J. Hydrogen Energy, 27, 453 (1997).

4. T.Ohmori, E.Enyo, T.Mizuno, Y.Nodasaka and H.Minagawa, Fusion Technology, 31, 210 (1997).

5. T.Mizuno, T.Ohmori and M.Enyo, J. New Energy, Vol 1, No.2, 37 (1996).

6. T.Mizuno, T.Ohmori and M.Enyo, J. New Energy, Vol. 1, No.3, 31 (1996).

7. T.Mizuno, T,Ohmori, K.Kurokawa, T.Akimoto, M.Kitaichi, K.Inoda. K.Azumi, S.Simokawa and M.Enyo, Denkikagaku 64, 1160 (1996).

8. T.Ohmori, T.Mizuno and M.Enyo, J. New Energy, Vol. 1, No.3, 90 (1996).

9. T.Ohmori, T.Mizuno and N.Enyo, Proc. ICCF-6 Toya, Japan, 670 (1996).

10. G.H.Miley, J. New Energy, Vol. 1, No.3, 1 (1996).

11. T.Ohmori, J. Electroanal. Chem., 157, 159 (1983).

12. J.Dash, G.Noble and D.Diman, Proc. ICCF-4, Lahaina, Hawaii, 25-1 (1994).

13. T.Ohmori and M.Enyo, Fusion Technology, 24, 293(1993). 